\title{
ESTUDOS DO LAZER NO BRASIL EM PRINCÍPIOS DO SÉCULO XXI: PANORAMA E PERSPECTIVAS
}

\author{
LEISURE STUDIES IN BRAZIL IN THE EARLY 21'st CENTURY: OVERVIEW AND \\ PERSPECTIVES
}
ESTUDIOS DEL OCIO EN BRASIL A PRINCIPIOS DEL SIGLO XXI: PANORAMA $Y$ PERSPECTIVAS

\author{
Cleber Dias*, Oromar Augusto dos Santos Nascimento*, \\ Marcos Dittmar Buba*, Ari Lazzarotti Filho*
}

Palavras chave: Atividades de lazer. Produção do conhecimento. Brasil.

\begin{abstract}
Resumo: Este estudo teve como objetivo apresentar um panorama sobre a produção do conhecimento em lazer no Brasil. Teve como metodologia uma análise bibliométrica dos artigos veiculados na revista Licere de 2000 a 2010. Nesse período, o número de artigos e de coautores por artigo aumentou significativamente. Os livros e autores brasileiros constituem as principais referências. A maioria dos autores que publicaram mais frequentemente tem formação em Educação Física. Tudo isso vai caracterizando uma estrutura ambivalente nos Estudos do Lazer no Brasil: por um lado, uma crescente autonomia desse campo de pesquisas como área especializada, com influência relativamente pequena de autores estrangeiros. Por outro lado, a mesma situação geral pode também caracterizar assimilação superficial das tradições das Ciências Humanas, além de certo isolamento com relação a trabalhos publicados fora do Brasil.
\end{abstract}

Abstract: This study presents an overview of leisure studies in Brazil. We conducted a bibliometric analysis of articles published on Licere magazine in 2000-2010. During that period, the number of articles and co-authors per article has increased significantly. Books and Brazilian authors are the main references. Most authors who have published more often are trained in Physical Education. All this characterizes an ambivalent structure in Brazilian leisure studies: on the one hand, increasing autonomy for the field of research as a specialty area, with relatively little influence by foreign authors; on the other hand, the same general situation can also characterize superficial assimilation of traditions from the Humanities as well as certain isolation regarding works published outside Brazil.

Palabras clave: Actividades Recreativas. Producción del conocimiento. Brasil.
Resumen: Este estudio tuvo como objetivo presentar una visión general de la producción del conocimiento acerca del ocio en Brasil. Tuvo como metodología un análisis bibliométrico de los artículos publicados en la Revista Licere entre 2000 y 2010. Durante este período, el número de artículos y de coautores por artículo aumentó significativamente. Los libros y autores brasileños son las principales referencias. La mayoría de los autores que publicaron con mayor frecuencia tienen una formación en Educación Física. Todo esto caracteriza una estructura ambivalente en los estudios del ocio en Brasil: por un lado, una creciente autonomía de este campo de investigación como un área especializada, con relativamente poca influencia de autores extranjeros. Por otro lado, la misma situación general puede también caracterizar una asimilación superficial de las tradiciones de las Humanidades, además de un cierto aislamiento con respecto a las obras publicadas fuera de Brasil.
*Universidade Federal de Minas Gerais. Belo Horizonte, MG, Brasil. E-mail: cleberdiasufmg@gmail.com marcosbuba.ef@hotmail.com

**Universidade de Brasília. Brasília DF, Brasil.

E-mail: oromar.augusto@gmail.com

***Universidade Federal de Goiás. Goiânia, GO, Brasil. E-mail: arilazzarotti@gmail.com

Recebido em: 12-07-2016 Aprovado em: 09-05-2017

(c) (i) () Licence 


\section{INTRODUÇÃO}

Todo campo de conhecimento necessita realizar periodicamente um balanço crítico a respeito dos seus rumos. Avaliar o acúmulo realizado por certa comunidade de especialistas em dado período de tempo é um procedimento essencial para melhor dimensionar as conquistas realizadas e os desafios ainda por realizar. Tudo isso pode ser especialmente importante para áreas do conhecimento mais recentes, como é o caso dos Estudos do Lazer. No Brasil, alguns trabalhos analisando diferentes fontes já ofereceram importantes contribuições nesse sentido (ALVES et al., 2011; 2012; GOMES, 2004; PEIXOTO, 2007; STOPPA et al., 2013).

Internacionalmente, 0 desenvolvimento histórico inicial dessa especialidade multidisciplinar remete ao período entre as décadas de 1960 e 1970, embora pesquisas acadêmicas e reflexões filosóficas a respeito do uso do tempo livre, de maneira mais genérica e imprecisa, datassem desde antes (SNAPE; PUSSARD, 2013). Apenas depois da Segunda Guerra Mundial, todavia, inicia-se a sistematização de argumentos que apontavam para a necessidade de organização de um campo de pesquisas especificamente dedicado ao estudo do lazer. Sociólogos europeus, com destaque para franceses e ingleses, estiveram entre os protagonistas internacionais desse processo. Nesse momento, a articulação teórica do lazer como uma categoria bem definida de análise social dizia respeito, basicamente, à identificação de atividades recreativas no tempo livre como elemento importante para reforçar ou contrabalancear os efeitos alienantes do trabalho. Em 1956, o francês Georges Friedmann (1972) apresentou influente livro sobre as consequências do trabalho industrial. Para Friedmann, a industrialização tornara 0 trabalho alienante e frustrante. Para amenizar esses efeitos, ele apontava para a necessidade de enriquecer o significado do trabalho para além da mera execução monótona e repetitiva de tarefas, mas também para as possibilidades de utilizar-se o lazer como complemento ou compensação para o trabalho alienante. Em outras palavras, Friedmann dimensionava o lazer como oportunidade para o desenvolvimento humano. Nos anos imediatamente posteriores à publicação da obra de Friedmann, formulações muito semelhantes, ainda que em termos ligeiramente diferentes, seriam apresentadas na Inglaterra por Robert Park, e sobretudo na França, por Joffre Dumazedier.

Em 1953, depois de uma trajetória de militância em ações ligadas à educação popular, 0 francês Joffre Dumazedier integrou-se, com apoio de Georges Friedmann, ao Centro Nacional para Pesquisa Científica (órgão de fomento científico francês), onde logo ajudou a criar uma equipe de Sociologia do Lazer e da Cultura Popular. Em 1956, Dumazedier sugeriu a criação de um grupo de trabalho sobre sociologia do lazer no âmbito da Associação Internacional de Sociologia (que foi criado e presidido por ele próprio até 1974), ao mesmo tempo em que iniciou a publicação de diversos estudos sobre o assunto. Em conjunto, essas iniciativas seriam depois apontadas como peças-chave do processo de autonomização dos estudos sobre 0 lazer com relação à sociologia do trabalho (SAMUEL, 1996).

Depois disso, diversas iniciativas, sem relações aparentemente diretas entre si, deflagraram-se quase simultaneamente em várias partes. Em 1975, iniciou-se, na Inglaterra, a publicação de conferências sobre Estudos do Lazer (Leisure Studies Conferece Papers) e a fundação da Associação de Estudos do Lazer (Leisure Studies Association). Em 1983, no mesmo contexto, foi lançado o Leisure Studies Journal, importante marco para a divulgação de pesquisas em língua inglesa, publicado até os dias de hoje. 
Em outros pontos da Europa, com diferentes graus de intensidade e organização, iniciativas semelhantes para sistematização de pesquisas sobre o lazer também foram deflagradas. A prosperidade econômica e o Estado de Bem-Estar Social que caracterizaram 0 período, associados ao aumento de fundos públicos para saúde, assistência social, educação e pesquisa, explicam parte do processo. Nessa época, formuladores de políticas públicas preocupavam-se cada vez mais com temas como a qualidade de vida, em que o lazer era visto como recurso potencialmente importante para esses propósitos. Ao mesmo tempo, cursos universitários eram ampliados e diversificados, favorecendo, assim, a criação de novos departamentos e carreiras, incluindo alguns dedicados ao lazer (MOMMAS, 1997).

No Brasil, de forma não muito diferente, uma série de iniciativas ligadas ao lazer começou a ser organizada de forma cada vez mais regular e sistemática a partir dos anos 1970, embora ações desse tipo pudessem também ser datadas desde antes (para ações anteriores aos anos 1970, ver ISAYAMA et al., 2014). Nessa época, segundo Sant'Anna (1994), consolidouse a compreensão de que atividades lúdicas para o descanso ou diversão eram importantes e potencialmente vantajosas para fins e interesses sociais. Como consequência, várias de iniciativas relativas ao uso do tempo livre foram deflagradas ou ampliadas, tais como colônias de férias, ruas de lazer, parques infantis, reservas ecológicas e clubes recreativos operários. No âmbito da produção do conhecimento sobre o assunto, o Serviço Social do Comércio (Sesc) desempenhou papel importantíssimo, organizando cursos, conferências, bibliotecas e publicações, o que acabou por fomentar a qualificação de profissionais que exerceriam grande protagonismo nos anos seguintes, como foi o caso de Renato Requixa.

Atualmente, de acordo com levantamento realizado em meados de 2015 na Plataforma de Grupos de Pesquisa do Conselho Nacional de Desenvolvimento Científico e Tecnológico (CNPq), órgão brasileiro para o fomento à pesquisa, existem cerca de 230 grupos de pesquisa no Brasil dedicados aos estudos de vários aspectos do lazer. Mesmo considerando que muitos desses grupos talvez não tenham relações reais e efetivas com o assunto, o que um levantamento desta natureza não seria capaz de determinar, a mera superioridade do número de grupos de pesquisa com relação àqueles apurados outrora por Souza e Isayama (2006) já evidencia, por si só, a dinâmica de crescimento e expansão deste campo de estudos. Além disso, tem-se um Programa de Pós-Graduação Interdisciplinar em nível de mestrado e doutorado, linhas de pesquisa em outros Programas de Pós-Graduação (principalmente na Educação Física), bem como disciplinas em diversos cursos de graduação universitária (notadamente nos cursos de Educação Física e Turismo). Têm-se ainda dois eventos realizados periodicamente: o Encontro Nacional de Recreação e Lazer (ENAREL, realizado desde 1989) e o Congresso Brasileiro de Estudos do Lazer (CBEL), que a partir de 2014 substituiu o Seminário o Lazer em Debate (criado em 2000). Dentre os periódicos científicos especializados, que servem como outro importante indicador da dinâmica acadêmica da especialidade, destacam-se a revista Licere e a recém-criada Revista Brasileira de Estudos do Lazer (RBEL), ligada à Associação Nacional de Pesquisa e Pós-Graduação em Lazer.

\section{METODOLOGIA}

Neste artigo, com o propósito de empreender uma reflexão a respeito de alguns sentidos recentes no desenvolvimento acadêmico dos Estudos do Lazer no Brasil, analisaremos a produção do conhecimento nessa área especializada. Mais especificamente, realizaremos uma 
análise bibliométrica ${ }^{1}$ dos artigos publicados na revista Licere de 2000 a 2010, correspondendo, portanto, a toda primeira década do século XXI. Os artigos originais e de revisão publicados nesse período totalizam 198 trabalhos, de 268 autores e coautores, publicados ao longo de 23 fascículos. Foram desconsiderados materiais de outras seções da revista, tais como relatos de experiências, entrevistas e resumos de dissertações ou teses. No material considerado, enfatizou-se uma análise sobre os autores (especialmente área de formação e titulação), assuntos privilegiados e referências bibliográficas (tipo de material e autores). Esses elementos permitem determinar as obras e autores mais citados, assuntos mais enfatizados, palavraschave mais utilizadas, autores que mais publicaram, bem como suas respectivas áreas de formação, revelando, assim, parte da dinâmica de produção do conhecimento desse campo de pesquisas. Inevitavelmente, outros importantes aspectos, mais sutis e difíceis de serem capturados em análises desse tipo, ficam ainda por examinar, tais como os métodos utilizados, a orientação teórica adotada ou as conclusões apresentadas.

Além disso, deve-se ainda destacar que há também um conjunto de outros trabalhos disponíveis sobre o assunto, para além dos artigos publicados na Licere, e que ofereceriam indicadores importantes, e talvez contraditórios, sobre os sentidos gerais da produção acadêmica sobre o lazer no Brasil. Uma busca pela palavra-chave "lazer" no Scielo (Scientific Eletronic Library Online), por exemplo, considerando, simultaneamente, todos os índices (título, autor e resumo), registrou, em maio de 2013, um total de 459 ocorrências em 129 revistas ${ }^{2}$. Desse total, 332 são da área de Ciências da Saúde (72\%) e apenas 97 da área de Ciências Humanas (21\%). O restante se distribui pelas áreas de Ciências Sociais aplicadas (5,4\%), Ciências Biológicas (3,9\%), Ciências Agrícolas (1,3\%), Engenharia (0,87\%) e Linguística, Letras e Artes. Baseando-se nesta base de dados, em particular, poder-se-ia depreender que o lazer no Brasil tem sido estudado prioritariamente no âmbito das Ciências da Saúde (medicina, enfermagem e saúde coletiva, sobretudo, excluindo dessa ênfase, porém, a Educação Física), em conclusão bastante diferente da que se pode chegar a partir dos artigos publicados na Licere, inteiramente inscritos na órbita das Ciências Humanas, apesar do protagonismo exercido por autores com formação em Educação Física, como veremos.

Assim, uma tentativa de analisar a produção sobre lazer no Brasil pode levar a resultados significativamente diferentes, de acordo apenas com o conjunto de informações selecionadas. Dado o volume documental disponível, porém, é ainda difícil vencer a parcialidade decorrente desta inevitável seletividade na revisão da produção acadêmica brasileira. Mesmo esforços notáveis, como os de Elza Peixoto (2007), que realizou amplo levantamento da produção sobre o lazer no Brasil, permanecem ainda incompletos. Talvez o acúmulo de iniciativas nessa direção vá concorrendo, pouco a pouco, para a composição de um quadro com menos lacunas.

Apesar dessas ponderações, o material veiculado na Licere ainda parece, de todo modo, bastante significativo, quer pela longevidade do periódico, quer pela sua natureza especializada. Não por acaso, outros autores já a tomaram como recurso para um balanço de aspectos particulares da produção acadêmica sobre o lazer, como as políticas públicas ou a formação profissional (ALVES et al., 2011; 2012; STOPPA et al., 2013). Além disso, artigos em periódicos, em detrimento de outros canais de vinculação científica, como dissertações, teses

$1 \mathrm{~A}$ bibliometria fornece indicadores do comportamento e desenvolvimento de uma área do conhecimento, e tem como objetivo a análise da produção científica, levando em consideração os autores, instituições, temas de estudo, bases epistemológicas que fundamentam os estudos (ARAÚJO; ALVARENGA, 2011). 
ou trabalhos em anais de eventos científicos, ocupam lugar de destaque no atual cotidiano acadêmico de muitos pesquisadores, dado que a orientação das políticas científicas brasileiras, a exemplo do que se passa em outros países, privilegia sobremaneira esse tipo de publicação. Como resultado, muitos pesquisadores, reagindo e tentando se conformar a tais exigências, têm canalizado suas principais produções para periódicos científicos, que se tornaram, assim, veículos capitais para difusão do conhecimento científico, em detrimento de outras formas de divulgação. ${ }^{3}$ A situação afeta até mesmo as Ciências Humanas, tradicionalmente ligadas aos livros como principal veículo para apresentação dos resultados de pesquisas. Segundo cálculos de Abel Packer (2011), em 2009, 49\% de todas as citações geradas por trabalhos da área de Ciências Humanas no Scielo Brasil já diziam respeito a periódicos, o que sugere uma progressiva mudança nos costumes de publicação e organização do trabalho acadêmico de cientistas sociais brasileiros.

\section{RESULTADOS E DISCUSSÕES}

A revista Licere foi criada em 1998 no âmbito do Centro de Estudos do Lazer da Universidade Federal de Minas Gerais. Atualmente, com periodicidade quadrimestral, 0 periódico está ligado ao Programa de Pós-Graduação Interdisciplinar em Estudos do Lazer, da mesma universidade. 0 número de fascículos e artigos publicados de 2000 a 2010 cresceu progressivamente ao longo desse período, conforme o Gráfico 1. A situação provavelmente exprime duas transformações simultâneas. Por um lado, o aumento do número de pesquisadores mais diretamente envolvidos com os Estudos do Lazer. Por outro, a expectativa desses pesquisadores, tácita ou declarada, de tentar atender exigências cada vez mais elevadas de produtividade intelectual lançadas para todas as áreas do conhecimento e que serão contabilizadas, antes de tudo, pelo número de artigos publicados em periódicos.

Gráfico 1 - Número de Fascículos e Artigos publicados na Licere de 2000 a 2010.

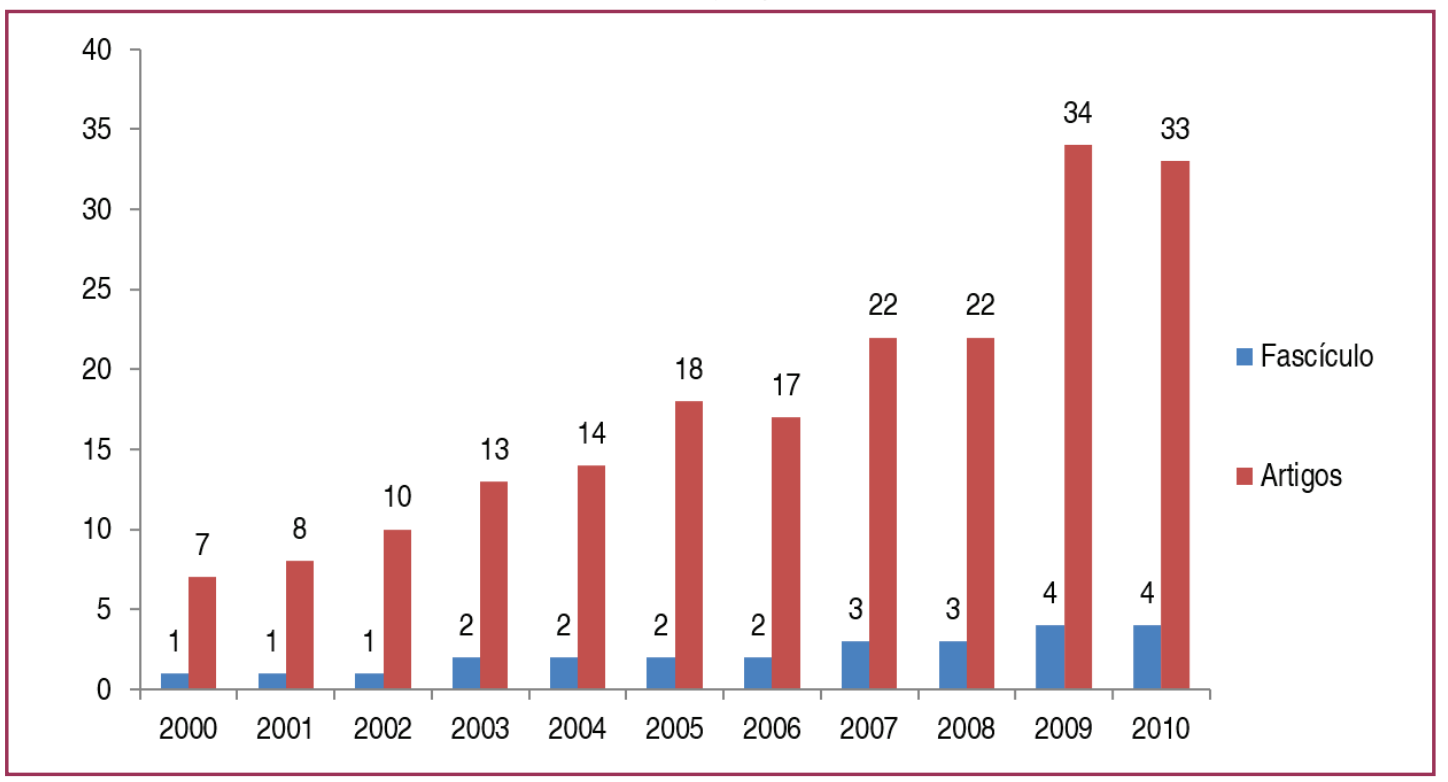

Fonte: Dados da pesquisa.

Aumentou também no período o número médio de autores por artigo, de tal maneira que, em 2010, poucos artigos contavam apenas um único autor, conforme o Gráfico 2. Conforme se

3 Para outras reflexões sobre influências diversas da política científica brasileira sobre estratégias e modos de fazer nos estudos sobre o lazer, ver STIGGER; MYSKIW, 2015; TSCHOKE, 2016. 
vê ainda no mesmo Gráfico, em 2010, a maioria dos artigos tinha já dois ou mais coautores. A transformação pode exprimir uma intensificação do trabalho de pesquisa colaborativa, ou apenas a reprodução de práticas eticamente questionáveis, em que professores ou coordenadores de laboratórios e grupos de pesquisa assumem a coautoria de trabalhos, com o propósito deliberado de incrementar artificialmente seus números de publicações e indicadores de produtividade, sem necessariamente ter relações intelectualmente autênticas com aquelas ideias e resultados. Tais situações têm se tornado tão frequentes, que o Conselho Nacional de Desenvolvimento Científico e Tecnológico (CNPq), após uma série de denúncias e episódios de condutas antiéticas em ambientes de pesquisa, chamou atenção para 0 assunto em suas diretrizes éticas. Segundo o documento, em seus tópicos 17 e 18, respectivamente:

17. Somente as pessoas que emprestaram contribuição significativa ao trabalho merecem autoria em um manuscrito. Por contribuição significativa entendese realização de experimentos, participação na elaboração do planejamento experimental, análise de resultados ou elaboração do corpo do manuscrito. Empréstimo de equipamentos, obtenção de financiamento ou supervisão geral, por si só não justificam a inclusão de novos autores, que devem ser objeto de agradecimento.

18. A colaboração entre docentes e estudantes deve seguir os mesmos critérios

[...] Autoria fantasma em Ciência é eticamente inaceitável (http://cnpq.br/diretrizes).

No caso da Licere, talvez apenas uma pesquisa qualitativa que ouvisse autores e coautores, alunos e professores pudesse determinar melhor a real natureza das motivações por trás do aumento do número de coautores nos artigos publicados nas páginas deste periódico. É digno de nota, porém, que muitas coautorias envolvem relações de orientação entre professores e seus alunos ou ex-alunos, ao passo que poucas dizem respeito à cooperação de dois ou mais professores.

Gráfico 2 - Número de autores por artigo 2000-2010.

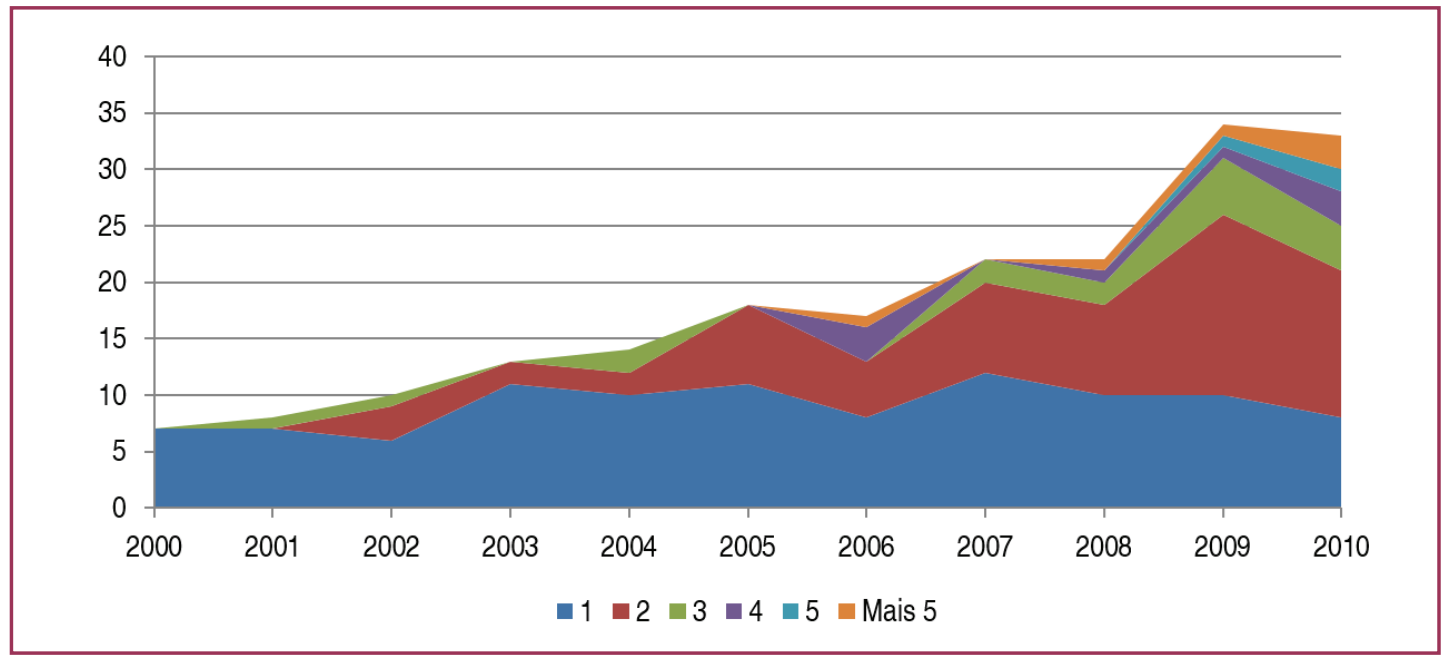

Fonte: Dados da pesquisa.

Em relação às palavras-chave dos artigos, o termo mais usado é "lazer", com 108 ocorrências. Em seguida, "atividades de lazer" e "cultura", com 37 e 20 ocorrências, respectivamente, conforme o Gráfico 3. Outras palavras-chave terão ocorrências crescentemente rarefeitas. A dificuldade de convergir na escolha de palavras-chave, para além do óbvio uso do "lazer" ou das "atividades de lazer", representa, de certo modo, uma dificuldade maior 
e mais importante, relacionada à delimitação de problemas de pesquisas comuns a serem compartilhados. Em outros termos, analisando mais detalhadamente trabalhos de alguns pesquisadores brasileiros frequentemente citados nesta área de estudos, Reis (2009) também destacou divergências dos temas centrais de pesquisas entre esses acadêmicos. A situação pode ser grave e importante, pois o progresso do conhecimento científico não é um gesto individual de genialidade, mas o resultado articulado e cumulativo do trabalho cooperativo de uma rede de pesquisadores. E a assimilação dos achados e resultados produzidos por outros pesquisadores é a mais elementar e indispensável das formas de cooperação para essas finalidades científicas.

Gráfico 3 - Palavras-chave mais recorrentes

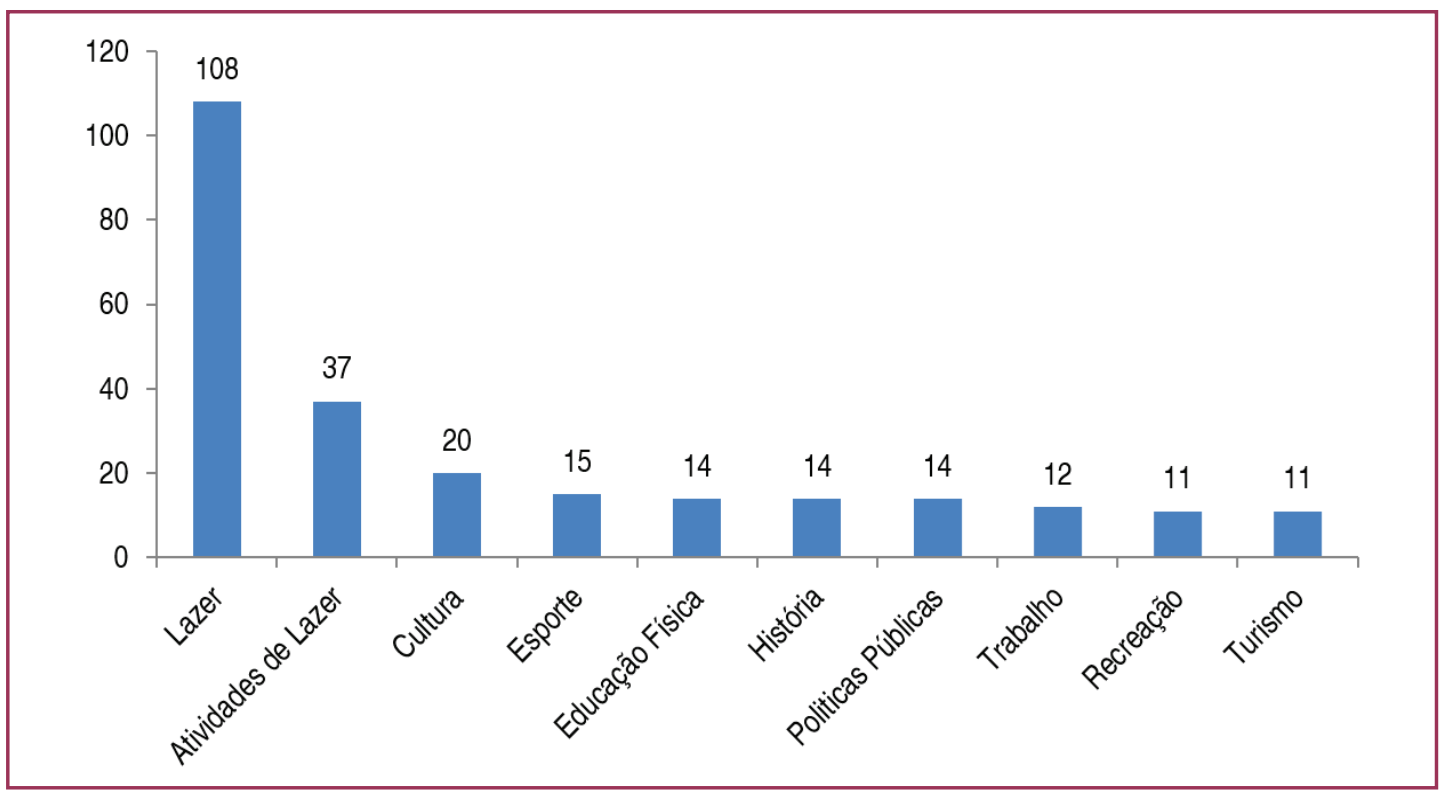

Fonte: Dados da pesquisa.

Conforme o Gráfico 4, a principal fonte de referências dos artigos publicados ainda são os livros, que respondem por $68,72 \%$ de todas as referências bibliográficas mencionadas no período. Apesar de todo o incentivo fornecido atualmente em favor dos artigos em periódicos pelo sistema de recompensas da política científica brasileira, eles correspondem apenas a 12,08\% do total de referências produzidas pela Licere entre 2000 e 2010. Ou seja, 0 aparente empenho dos especialistas brasileiros em lazer por atenderem expectativas de muitas publicações, sobretudo em periódicos, expresso, entre outras coisas, no crescimento do número de artigos disponibilizados para publicação na própria Licere, ainda não minou a importância atribuída aos livros. Sequer artigos publicados na própria Licere são privilegiados no material citado, o que, além da tradicional valorização dos livros como fonte de consulta, pode ser também a expressão de outro importante obstáculo para o desenvolvimento dos Estudos do Lazer.

Do total das 4.038 referências bibliográficas indicadas pelos 198 artigos originais e de revisão publicados no período, apenas $74(1,83 \%)$ citam artigos publicados na própria Licere. Mesmo artigos com temáticas afins são frequentemente ignorados pelos autores, que não parecem preocupados em estabelecer canais de interlocução, críticos ou elogiosos, com os achados e conclusões já disponibilizados por outros pesquisadores. Nesse sentido, a avaliação de Burdge (1983) sobre o cenário anglo-saxão de produção do conhecimento em Estudos 
do Lazer em princípios da década de 1980, ao menos em um aspecto, parece bastante semelhante à situação brasileira de princípios do século XXI. Segundo ele, esse campo de pesquisas via pouco acúmulo dos seus achados de pesquisa. Por vezes, dizia Burdge, até mesmo a formulação de problemas de pesquisa parecia pouco enraizada na literatura disponível. De maneira análoga, na produção brasileira vinculada pela Licere na primeira década do século XXI, nota-se mesmo certo desprezo pelos resultados apresentados nesse próprio periódico, que, de outro modo, deveriam funcionar como uma espécie de repositório a ser obrigatoriamente consultado. Paradoxalmente, a comunidade brasileira de pesquisadores em lazer parece subestimar material recente produzido por eles mesmos, preferindo referências canônicas mais antigas, elevadas agora à condição de "clássicos".

Gráfico 4 - Tipos de referências dos artigos

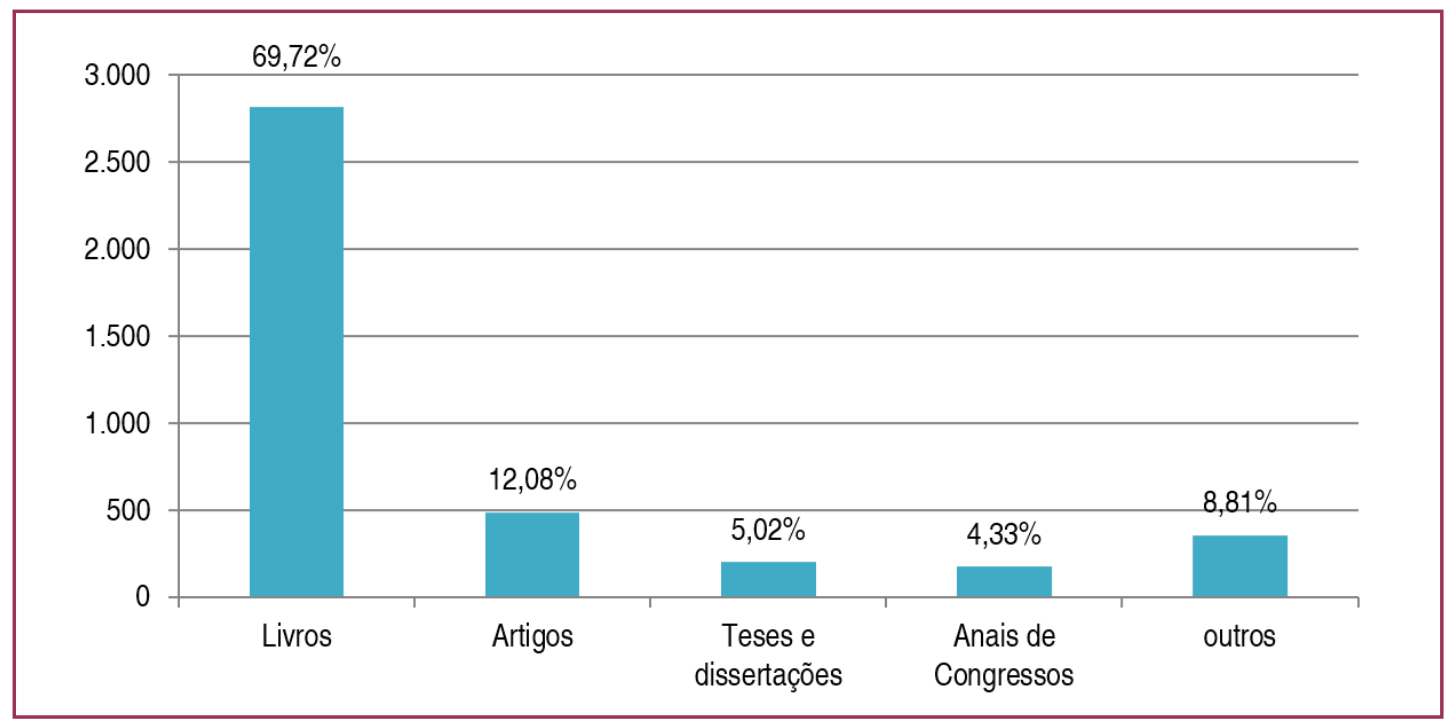

Fonte: dados da pesquisa.

O autor mais vezes citado foi Nelson Carvalho Marcellino, responsável por três das quatro obras mais citadas, a saber, os livros Lazer e educação, Lazer e Humanização e Estudos do lazer: uma introdução. Mesmo desconsiderando as autocitações produzidas pelo próprio Marcellino (que somam 38 ocorrências ou $21 \%$ do total de citações recebidas por ele), que foi também o autor que mais publicou artigos neste periódico no período, ele segue, com vantagem, como a referência mais relevante. Marcellino foi a referência mais frequente para cinco dos dez autores que mais publicaram na Licere no período (ver Tabela 3). A situação pode revelar respeito e consideração pelo conhecimento produzido no passado, o que pode ser especialmente importante para o desenvolvimento de qualquer campo de pesquisa, uma vez que oferece subsídios para a elaboração criativa e o progresso das fronteiras do conhecimento. Todavia, a mesma situação pode revelar também uma espécie de mera formalidade forjada pelos usos e costumes, esvaziando, inclusive, a própria dimensão crítica das obras e autores citados, que se transformam, então, em meros argumentos de autoridade de um sistema de deferência capaz até de inibir a necessária energia criativa para inovação de uma área de estudos.

Outro dado interessante é o relativo predomínio de autores brasileiros nas referências utilizadas. De modo geral, do volume total de referências produzidas pelos artigos publicados no período, $25 \%$ remetiam a autores estrangeiros, ao passo que $64 \%$ eram brasileiros $(11 \%$ das referências não puderem ser identificados ou eram fontes de outra natureza, que não 
propriamente bibliográfica). De todos os dez autores mais citados, apenas três são estrangeiros: Joffre Dumazedier, Karl Marx e Norbert Elias. Dentre esses autores estrangeiros mais citados, apenas Dumazedier é mais diretamente relacionado aos Estudos do Lazer, destacando-se seu livro Sociologia empírica do lazer. Já Marx e Elias são referências teóricas mais gerais, embora o último tenha também se notabilizado por trabalhos relacionados especificamente ao lazer.

Esses números vão revelando situação ambígua aos propósitos de desenvolvimento dos Estudos do Lazer no Brasil. Ao mesmo tempo em que o número relativamente reduzido de referências a nomes alheios aos Estudos do Lazer, especificamente, pode desempenhar um papel positivo no desenvolvimento deste campo de estudos, na medida em que expressa maior autonomia, a situação pode também expressar uma relativa escassez ou mesmo superficialidade no diálogo com temas mais gerais das Ciências Humanas, o que pode condicionar negativamente o desenvolvimento desse campo de pesquisas especializado, especialmente pelo risco de uma apropriação incipiente das tradições teóricas, metodológicas e narrativas das Ciências Humanas, em que estão radicados os Estudos do Lazer. Poucas referências a estudos produzidos nas Ciências Humanas, de maneira geral, podem ainda denotar pouco compromisso em fazer o estudo do lazer, em particular, colaborar para o desenvolvimento de compreensões sobre dinâmicas sociais mais gerais - o que contraria a própria finalidade, em última instância, de qualquer ramo das Ciências Humanas, incluindo aí os Estudos do Lazer. Da mesma forma, o número relativamente reduzido de referências estrangeiras nos artigos publicados na Licere no período é dotado também de certa ambiguidade. Por um lado, pode representar certa independência com relação à produção em língua inglesa, que usualmente exerce papel hegemônico sobre a agenda de pesquisas de inúmeras áreas do conhecimento, ao mesmo tempo em que pode representar também, de modo negativo, isolamento e pouca consideração por importantes achados e resultados apresentados por estudos publicados fora do Brasil, que seguramente poderiam oferecer dados, insights ou chaves interpretativas originais para os problemas de pesquisas em discussão.

Tabela 1 - Autores e obras mais citados

\begin{tabular}{cccc}
\hline Autor & Obra & & \\
& Lazer e educação & 30 & \\
& Estudos do lazer: uma introdução & 22 & 178 \\
Nelson C. Marcellino & Lazer e humanização & 17 & \\
& Pedagogia da animação & 69 & \\
& Outras obras diversas & 20 & \\
& Sociologia empírica do lazer & 19 \\
Joffre Dumazedier & Lazer e cultura popular & 16 & \\
& Valores e conteúdos culturais do lazer & 40 & \\
& Outras obras diversas & 20 & \multirow{2}{*}{88} \\
\hline \multirow{2}{*}{ Victor A. de Melo } & Introdução ao lazer & 68 & \\
& Outras obras diversas & 12 & 47 \\
Luis O. Camargo & Educação para o lazer & 12 & 47 \\
& O que é o lazer & 23 & 45 \\
\hline Heloísa Bruhns & Outras obras diversas & 45 & 45
\end{tabular}


Continuação da tabela $1 . .$.

\begin{tabular}{|c|c|c|c|}
\hline Karl Marx & $\begin{array}{c}\text { O capital } \\
\text { Outras obras diversas }\end{array}$ & $\begin{array}{c}9 \\
24\end{array}$ & 33 \\
\hline Gisele Schwartz & Obras diversas & 30 & 30 \\
\hline \multirow{3}{*}{ José G. C. Magnani } & Festa no pedação: cultura popular e lazer na cidade & 12 & \multirow{3}{*}{28} \\
\hline & Na metrópole: textos de antropologia urbana & 8 & \\
\hline & Outras obras diversas & 8 & \\
\hline \multirow{3}{*}{ Christianne L. Gomes } & Significados de recreação e lazer no Brasil (tese) & 6 & \multirow{3}{*}{27} \\
\hline & Dicionário crítico do lazer & 3 & \\
\hline & Outras obras diversas & 18 & \\
\hline \multirow{3}{*}{ Fernando Mascarenhas } & Entre o ócio e o negócio (tese) & 6 & \multirow{3}{*}{23} \\
\hline & Lazer e grupos sociais: concepção e métodos & 5 & \\
\hline & Outras obras diversas & 12 & \\
\hline \multirow{3}{*}{ Norbert Elias } & A busca da excitação & 8 & \multirow{3}{*}{20} \\
\hline & O processo civilizador & 5 & \\
\hline & Outras obras diversas & 7 & \\
\hline
\end{tabular}

Fonte: dados da pesquisa.

Dentre os 268 autores que publicaram na revista no período, 59 (22\%) voltaram a publicar ao menos uma vez mais (Gráfico 5). Entre estes autores com mais de uma publicação, Nelson Carvalho Marcellino é o que mais publicou, contando 15 artigos. Depois dele, Victor Andrade de Melo aparece com a segunda maior quantidade de publicações no período, com oito artigos (ver Tabela 3). Analisando as referências utilizadas pelos 11 autores que mais publicaram na revista no período, percebemos que a autocitação não é uma prática tão comum, embora se faça presente, predominando entre quatro deles (ver Tabela 3).

Gráfico 5 - Número de autores que publicaram duas ou mais vezes

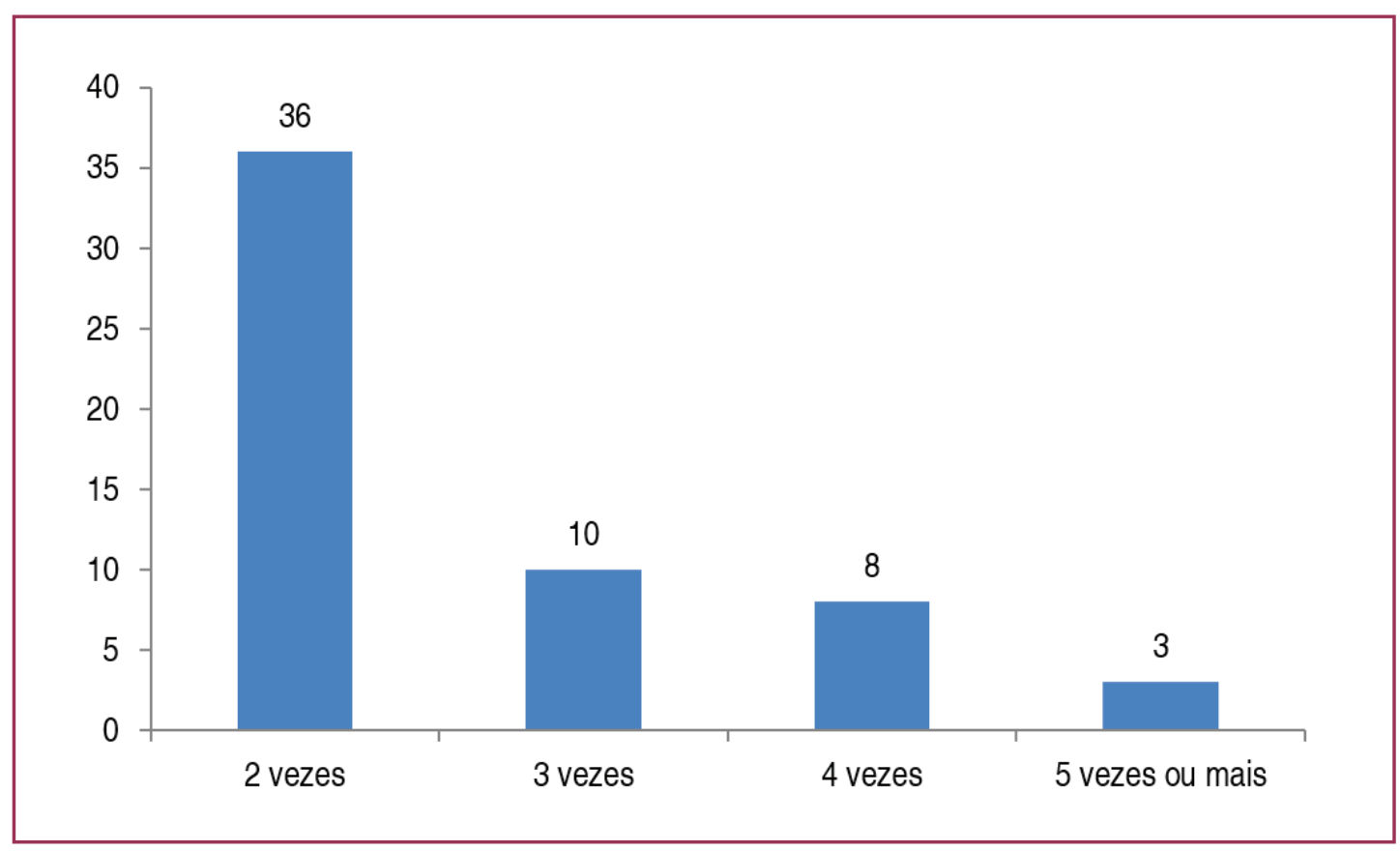

Fonte: Dados da pesquisa. 
Tabela 3 - Autores com quatro ou mais artigos publicados e suas referências mais frequentes

\begin{tabular}{|c|c|c|c|}
\hline Autor & Publicações & Referências mais frequentes & Citações \\
\hline \multirow{3}{*}{ Nelson C. Marcellino } & \multirow{3}{*}{15} & Nelson C. Marcellino & 38 \\
\hline & & Joffre Dumazedier & 16 \\
\hline & & Domenico De Masi & 12 \\
\hline \multirow{3}{*}{ Victor A. de Melo } & \multirow{3}{*}{8} & Victor A. de Melo & 7 \\
\hline & & Walter Benjamin & 2 \\
\hline & & Pierre Bourdieu & 2 \\
\hline \multirow{2}{*}{ Cleber Dias } & \multirow{2}{*}{6} & Victor A. de Melo & 7 \\
\hline & & Cleber Dias & 7 \\
\hline \multirow{3}{*}{ Alcyane Marinho } & \multirow{3}{*}{4} & Alcyane Marinho & 6 \\
\hline & & Michel Maffesoli & 5 \\
\hline & & Nelson C. Marcellino & 5 \\
\hline Cinthia L. da Silva & 4 & Nelson C. Marcellino & 5 \\
\hline \multirow{2}{*}{ Giovani De Lorenzi Pires } & \multirow{2}{*}{4} & Nelson C. Marcellino & 8 \\
\hline & & Joffre Dumazedier & 3 \\
\hline Giuliano G. de A. Pimentel & 4 & Nelson C. Marcellino & 5 \\
\hline \multirow{3}{*}{ Hélder F. Isayama } & \multirow{3}{*}{4} & Nelson C. Marcellino & 9 \\
\hline & & Hélder F. Isayama & 4 \\
\hline & & Christianne L. Gomes & 4 \\
\hline \multirow{3}{*}{ Heloísa T. Bruhns } & \multirow{3}{*}{4} & Michael Maffesoli & 8 \\
\hline & & Heloísa T. Bruhns & 7 \\
\hline & & Alcyane Marinho e Heloísa T. Bruhns & 3 \\
\hline \multirow{2}{*}{ Olívia C. F. Ribeiro } & \multirow{2}{*}{4} & Luis Otávio Camargo & 3 \\
\hline & & Joffre Dumazedier & 3 \\
\hline Junior Vagner P. da Silva & 4 & Nelson C. Marcellino & 11 \\
\hline
\end{tabular}

Conforme a Tabela 4, a formação destes autores que publicaram mais frequentemente na revista entre 2000 e 2010 tem claro predomínio da Educação Física, desde a formação inicial $(69,2 \%)$, até os graus de mestrado $(72,7 \%)$ e doutorado $(81,8 \%)$, reforçando compreensão já estabelecida a respeito das históricas relações entre Educação Física e Estudos do Lazer no Brasil (GOMES, 2008). Isayama e Melo (2014, p.774), editores da Licere, comentaram novamente o assunto recentemente, ao apresentarem uma reflexão sobre o periódico. Segundo eles:

Na verdade, um olhar panorâmico para esses anos de existência de Licere nos permite perceber o quanto sua trajetória tem relação com o trato do seu tema central no âmbito das iniciativas relacionadas à Educação Física. Isso se explicita não só na vinculação institucional de muitos dos protagonistas dos Estudos do Lazer no Brasil, como também na presença do assunto em coleções, periódicos e eventos da área [da Educação Física], entre os quais o Congresso Brasileiro de Ciências do Esporte, que possui um Grupo de Trabalho Temático específico.

Se o desenvolvimento histórico inicial dos Estudos do Lazer em países europeus ou anglo-saxões fora marcado por uma ativa participação de pesquisadores treinados em disciplinas tradicionais das Ciências Humanas (BURDGE, 1983), com destaque para a Sociologia, tudo indica não ter sido este, regra geral, o caso brasileiro. Tal situação condiciona de muitas formas os rumos do desenvolvimento dos Estudos do Lazer no Brasil. A proximidade da Educação Física às Ciências da Saúde, em detrimento de suas interfaces com as Ciências 
Humanas, que ocupam, então, lugar secundário, senão totalmente acessório nesse contexto, acaba por enquadrar as formas de apresentação dos resultados de pesquisa de uma maneira mais ortodoxa. A apresentação dos procedimentos metodológicos, por exemplo, menos do que princípios gerais de rigorosidade metódica, tende a ser vista como um conjunto de procedimentos normativos, isto é, uma espécie de passo a passo a ser inflexivelmente observado, tal como se pratica em outras áreas do conhecimento, especialmente nas Ciências Médicas ou Naturais, em que a padronização de procedimentos metodológicos pode ocorrer mais frequentemente, mas de forma inabitual ou até estranha à tradição das Ciências Humanas, em que o objeto de pesquisa e seus métodos são construídos pelo próprio pesquisador (BOURDIEU; CHAMBOREDON; PASSERON, 2007). Nesse sentido, nas Ciências Humanas, apresentar a classificação metodológica adotada por um estudo, como fenomenológico ou materialista histórico, por exemplo, cumpre uma formalidade, mas em verdade diz pouco a respeito de seus procedimentos efetivos. Mais que apenas nomear métodos e procedimentos como se estivessem confinados a um conjunto de regras fixas e imutáveis, interessa expor, detalhadamente e com rigor, os caminhos por meio dos quais os objetos de pesquisa foram construídos, examinando as condições de validade das técnicas, métodos ou procedimentos adotados nos casos e circunstâncias específicas em que foram utilizados.

Tabela 4 - Formação dos autores que mais publicaram na revista

\begin{tabular}{lcccccc}
\hline & Graduação & $\%$ & Mestrado & $\%$ & Doutorado & $\%$ \\
\hline Educação Física & 9 & $69,2 \%$ & 8 & $72,7 \%$ & 9 & $81,8 \%$ \\
Filosofia & 0 & $0,0 \%$ & 1 & $9,1 \%$ & 0 & $0,0 \%$ \\
História comparada & 0 & $0,0 \%$ & 1 & $9,1 \%$ & 0 & $0,0 \%$ \\
Ciências Sociais & 1 & $7,7 \%$ & 0 & $0,0 \%$ & 0 & $0,0 \%$ \\
Educação & 1 & $7,7 \%$ & 1 & $9,1 \%$ & 2 & $18,2 \%$ \\
Economia & 1 & $7,7 \%$ & 0 & $0,0 \%$ & 0 & $0,0 \%$ \\
Treinamento em esportes & 1 & $7,7 \%$ & 0 & $0,0 \%$ & 0 & $0,0 \%$ \\
\hline Total & $13^{4}$ & $100 \%$ & 11 & $100,0 \%$ & 11 & $100 \%$ \\
\hline & & Fonte: Dados da pesquisa. & & &
\end{tabular}

Protagonizado por autores formados, em larga medida, na Educação Física, quando não inseridos institucionalmente em departamentos ou faculdades desta área do conhecimento, ao mesmo tempo em que academicamente atuantes no âmbito das Ciências Humanas, produzindo, assim, pesquisas orientadas pela Filosofia, Sociologia, História, Antropologia ou outra disciplina deste mesmo universo, os Estudos do Lazer no Brasil tendem a assumir, neste cenário, uma feição híbrida, combinando elementos típicos dessas duas formas de produção do conhecimento: as Ciências Humanas, de um lado; e as Ciências da Saúde, de outro.

\section{CONSIDERAÇÕES FINAIS}

O escopo e o perfil editorial da Licere expressam características gerais que marcam os Estudos do Lazer, não apenas no Brasil, mas também internacionalmente. Parte dessas

4 A divergência entre os números da formação na graduação, mestrado e doutorado acontece porque dois autores têm duas graduações em seus currículos. Como estamos levando em consideração os autores que publicaram quatro artigos ou mais, totalizando 11 indivíduos, temse que dois deles têm duas graduações, totalizando, assim, 13 cursos de graduação. Todos esses autores, por outro lado, só cursaram um mestrado e um doutorado cada, por isso o número final é 11 para mestrado e doutorado. 
características diz respeito a uma dimensão multidisciplinar orientada por e para as Ciências Humanas, assimilando, portanto, tradições desta área do conhecimento. Todavia, no caso específico do Brasil, muito bem representado no perfil dos autores que mais publicaram na Licere entre 2000 e 2010, para além da sua inserção no universo das Ciências Humanas, a histórica relação dos Estudos do Lazer com a Educação Física se impõe como outro traço peculiar. $\mathrm{O}$ aparente predomínio de reflexões teóricas ou conceituais, com menos ênfase na apresentação de resultados de pesquisa empíricas originais, já apontado por artigos de revisão que tomaram como fonte estudos publicados na Licere (ALVES et al., 2011; 2012; STOPPA et al., 2013), pode ser uma das consequências de tais características, além de operar como um obstáculo ao desenvolvimento desse campo de pesquisas. Estudos de natureza mais teórica ou conceitual tendem a estar concentrados em analisar concepções e abordagens canonizadas por uma dada comunidade de pesquisadores, ao invés do diálogo com a apresentação de resultados empíricos mais recentes. Essa postura pode acabar por inibir a desejável interlocução entre autores de pesquisas dedicadas a um mesmo tópico, o que talvez explique a baixa ocorrência de referências aos artigos publicados na própria Licere, ao mesmo tempo em que justifica o grande número de referências a trabalhos frequentemente tomados atualmente como "clássicos" dos Estudos do Lazer, como são algumas obras de Marcellino ou Dumazedier.

Embora interessante e até necessária em muitos aspectos, a ênfase sobre discussões teóricas talvez devesse, de agora em diante, ceder mais espaço para a apresentação dos resultados das pesquisas propriamente ditas, ao invés das circulares e por vezes monótonas discussões acerca de premissas ou pressupostos teóricos. A assimilação dos resultados de pesquisas já apresentadas fortalece a necessária interação colaborativa entre autores dedicados a um mesmo tópico de pesquisa, o que estimula 0 acúmulo de resultados e a consequente facilitação do progresso do conhecimento. Tal como praticado atualmente nos Estudos do Lazer no Brasil, a julgar pelo padrão de citações adotado pelos artigos publicados na Licere de 2000 a 2010, a importante e necessária consideração às pesquisas já realizadas e disponíveis é excessivamente seletiva e restringe-se apenas a autores consagrados. A massa de dados produzida por um pequeno exército de pesquisadores - nesse caso, de 268 autores e coautores - permanece obscura, quase inteiramente desprezada mesmo por seus pares. Faltar-lhes-ia profundidade, originalidade ou excelência suficientes para serem finalmente tomados mais a sério? Se sim, por que então teriam sidos publicados, com anuência de seus pares que depois os desprezarão? Se não, por que então tais artigos são tão sistematicamente ignorados? Não deve ser inteiramente desprezível o fato de que os autores que vinculam suas pesquisas na Licere competem também entre si por uma posição na hierarquia do ainda recente campo de especialidade dos Estudos do Lazer, em que citações e referências podem funcionar como um sistema de alianças ou de oferta de prestígio.

\section{REFERÊNCIAS}

ALVES, Cátia et al. Lazer e políticas públicas, no setor governamental: análise da revista Licere.

Revista Brasileira de Ciência e Movimento, v. 19, p. 78-89, 2011.

ALVES, Cátia et al. Lazer, políticas públicas não governamentais e estudos conceituais, na revista Licere. Revista da Educação Física, v. 23, p. 239-249, 2012. 
ARAÚJO, Rodrigo Ferreira; ALVARENGA, Lídia. A bibliometria na pesquisa cientíica da pósgraduação brasileira de 1987 a 2007. Encontros Bibli: revista eletrônica de biblioteconomia e ciência da informação, 15 mar. 2011. Disponível em: <https://periodicos.ufsc.br/index.php/eb/article/ view/1518-2924.2011v16n31p51>. Acesso em: 11 mar. 2016.

BOURDIEU, Pierre; CHAMBOREDON, Jean-Claude; PASSERON, Jean-Claude. Ofício de sociólogo: metodologia da pesquisa na sociologia. 6. ed. Petrópolis: Vozes, 2007.

BURDGE, Rabel J. Making leisure and recreation research a scholarly topic: views of a journal editor, 1972-1982. Leisure Sciences, v. 6, n. 1, p. 99-126, 1983.

FRIEDMANN, Georges. 0 trabalho em migalhas: especialização e lazeres. São Paulo: Perspectiva, 1972.

GOMES, Christianne Luce. Lazer, trabalho e educação: relações históricas, questões contemporâneas. Belo Horizonte: Ed. da UFMG, 2008.

GOMES, Cristina Marques. Pesquisa científica em lazer no Brasil: bases documentais e teóricas. 2004. 134f. Dissertação (Mestrado em Comunicação) - Universidade de São Paulo, São Paulo, 2004.

ISAYAMA, Helder Ferreira [et al.]. O esporte como alternativa de lazer: análise de experiências brasileiras. In: MARINHO, Alcyane; NASCIMENTO, Juarez Vieira do; OLIVEIRA, Amauri Aparecido Bássoli (Orgs.). Legados do esporte brasileiro. Florianópolis: Ed. da UDESC, 2014. p. 303-330.

ISAYAMA, Helder Ferreira; MELO, Victor Andrade de Melo. Licere: uma revista brasileira de lazer. Revista Brasileira de Ciências do Esporte, v. 36, n. 4, p. 773-779, 2014.

MOMMAAS, Hans. European leisure studies at the crossroads? A history of leisure research in Europe. Leisure Sciences, v. 19, n. 4, p. 241-254, Oct. 1997.

PACKER, Abel. Os periódicos brasileiros e a comunicação da pesquisa nacional. Revista USP, n. 89, p. 26-61, mar. / maio 2011.

PEIXOTO, Elza. Levantamento do estado da arte nos estudos do lazer: (Brasil) séculos XX e XXI alguns apontamentos. Educação e Sociedade, v. 28, n. 99, p. 561-586, maio/ago. 2007.

SAMUEL, Nicole. The Prehistory and History of Leisure Research in France. In: MOMMAAS, Hans (Ed.). Leisure research in Europe: methods and traditions. Wallingford: CAB International, 1996. p. 11-37.

SNAPE, Robert; PUSSARD, Helen. Theorizations of leisure in inter-war Britain. Leisure Studies, v. 32, n. 1, p. 1-18, 2013.

SOUSA, Alexandre Pierre Teixeira; ISAYAMA, Helder Ferreira. Lazer e educação física: análise dos grupos de pesquisa em lazer cadastrados na plataforma LATTES do CNPQ. Revista Digital EF Deportes, v. 11, n. 99, 2006. Disponível em: <http://www. efdeportes.com/efd99/cnpq.htm>. Acesso em: 7 jul. 2016.

STIGGER, Marco Paulo; MYSKIW, Mauro. O lazer entre a conteudização e a compreensão: olhares das subáreas da educação física. In: STIGGER, Marco Paulo (Org.). Educação Física + Humanas. Campinas: Autores Associados, 2015. v. 1, p. 155-180.

REIS, Leoncio José de Almeida. Novos atores em cena nos estudos do lazer no Brasil: possíveis diálogos a partir da teoria configuracional. 2009. 181 f. Dissertação (Mestrado) - Programa de PósGraduação em Educação Física, Universidade Federal do Paraná, Curitiba, 2009. 
STOPPA, Edmur A. et al. A produção do conhecimento na área do lazer: uma análise sobre a revista Licere. Pensar a Prática, v. 16, n. 3, p. 639654, jul./set.2013.

TSCHOKE, Aline. Da recreação e lazer para o lazer e sociedade: as maneiras de fazer acadêmico no campo do lazer ligadas a área da Educação Física. 2016. 198 f. Tese (Doutorado) - Programa de Pós-Graduação em Educação Física, Universidade Federal do Paraná, Curitiba, 2016. 


\section{Agradecimentos:}

Este estudo foi desenvolvido no contexto do projeto de pesquisa "Conocimiento e interés de la investigación en ocio, recreación, tiempo libre y lazer en América Latina", coordenado pelo Prof. José Fernando Tabares Fernández, da Universidade de Antioquia, Colômbia, a quem agradecemos pelo valioso estímulo. Agradecemos também a Elena Paz Morales, Julia Gerlero, Loreley Conde e Víctor Alonso Molina Bedoya, de diferentes países, com quem tivemos a rica oportunidade de discutir aspectos da produção de conhecimento sobre lazer na América Latina. Este estudo não contou com apoio financeiro de nenhum órgão ou agência de fomento. 